\title{
Reformulações da teoria marxista no enfoque pós- marxista de Laclau e Mouffe
}

\section{Reformulations of the marxist theory in the post- marxist approach of Laclau and Mouffe}

\author{
Ana Rodrigues Cavalcanti Alves ${ }^{4}$
}

\section{Resumo}

Este trabalho visa investigar as continuidades e descontinuidades da tradição marxista no pós-marxismo de Ernesto Laclau e Chantal Mouffe, a partir da identificação de conceitos e formas discursivas oriundos do marxismo que são reelaborados pelos autores na transição para o enfoque pós-marxista. Para tanto, analisamos de que maneira as categorias de materialismo, antagonismo e hegemonia são reformuladas para compor o aparato conceitual do pós-marxismo. A análise permite perceber que a tentativa de radicalização do materialismo de Marx se desdobra em uma Teoria do Discurso, a afirmação do caráter constitutivo do antagonismo conduz à impossibilidade de toda objetividade e a nova abordagem da hegemonia conduz à reformulação da noção de socialismo do marxismo. A partir dessa análise, é possível discutir a pertinência de se interpelar os autores clássicos a partir de uma perspectiva desconstrucionista que conduz à desconstrução de seus elementos constitutivos.

Palavras-chave: Desconstrução. Tradição Marxista. Ernesto Laclau. Chantal Mouffe.

\section{Abstract}

\footnotetext{
4 Pós-doutoranda do Programa de Pós-Graduação em Sociologia da Universidade Federal de Pernambuco (UFPE); ORCID: https://orcid.org/0000-0001-9121-882X; Email: anarodrigues86@gmail.com.
} 
This work aims to investigate the continuities and discontinuities of the Marxist tradition in Ernesto Laclau and Chantal Mouffe's post-Marxism, from the identification of concepts and discursive forms derived from Marxism that are reworked by the authors in the transition to the post-Marxist approach. Therefore, we analyze how the categories of materialism, antagonism and hegemony are reformulated to compose the conceptual apparatus of post-Marxism. This analysis allows us to understand that the attempt to radicalize Marx's materialism unfolds in a Discourse Theory, the constitutive character of antagonism leads to the impossibility of all objectivity and the new approach of hegemony leads to the reformulation of marxist socialism notion. From this analysis, it is possible to discuss the pertinence of questioning the classic authors from a deconstructionist perspective that leads to the deconstruction of its constituent elements.

Key-words: Deconstruction. Marxist Tradition. Ernesto Laclau. Chantal Mouffe.

\section{Introdução}

Seria a desconstrução derrideana uma forma de dialogar com autores clássicos? Para Ernesto Laclau e Chantal Mouffe a resposta é afirmativa. Os autores recorrem à perspectiva desconstrucionista proposta por Jacques Derrida como tentativa de restaurar a teoria marxista, que, segundo eles, havia chegado a um “ponto morto" na década de 1970, depois de um período excepcionalmente rico nos anos 1960 que teve seu epicentro no althusserianismo e em um renovado interesse em Gramsci e nos teóricos da Escola de Frankfurt (Laclau e Mouffe, 2010, p. 8). Segundo eles, os limites de uma possível expansão do marxismo estavam ligados às dificuldades de adequar as categorias marxistas às crescentes transformações da sociedade capitalista e à crise de toda uma concepção de socialismo, decorrente da observação da experiência dos países socialistas.

O enfoque pós-marxista proposto pelos autores, a partir de meados dos anos 1980, visa responder ao crescente hiato entre a lógica estrutural do marxismo e as novas configurações do capitalismo tardio, assumindo como objetivo teórico suprir as lacunas da teoria marxista, além do objetivo político de fornecer um aparato 
teórico que orientasse as esquerdas na construção de um projeto hegemônico - já que os partidos de esquerda estavam desorientados com a crise do socialismo real e emergência de uma hegemonia neoliberal. Contudo, o novo enfoque provocou um verdadeiro abalo nas diversas tentativas de renovação do marxismo, uma vez que ele se ancora numa perspectiva desconstrucionista como meio de reformular esta tradição, tentando reconstruí-la através de uma genealogia do presente, de um questionamento da teoria à luz dos problemas contemporâneos, o que implica necessariamente, segundo os autores, a desconstrução de seus elementos constitutivos.

Laclau e Mouffe (2010, p. 10) afirmam que o seu enfoque pós-marxista deve ser entendido como tentativa de reapropriação de uma tradição intelectual, mas também como esforço de ir além dela, uma vez que as categorias do marxismo não dão conta da complexidade do social. Nesse sentido, o referencial teórico dos autores está fortemente ancorado nas correntes contemporâneas que rejeitam posturas essencialistas e ressaltam o espaço de indeterminação nas relações sociais e políticas. Campos teóricos como a psicanálise, o pós-estruturalismo, a linguística estrutural e a filosofia analítica contribuem para a formação do arcabouço teórico pós-marxista, que coloca em xeque o essencialismo, o objetivismo e o determinismo da tradição marxista.

Diante da reformulação radical da teoria marxista ancorada numa perspectiva que desconstrói os seus elementos constitutivos e de um aparato teórico fortemente influenciado por correntes de pensamento contemporâneas, cujos pressupostos ontológicos e epistemológicos colidem diretamente com aqueles do marxismo, este trabalho visa analisar as continuidades e descontinuidades da tradição marxista no pós-marxismo de Laclau e Mouffe. A questão central neste trabalho é a de saber de que maneira os elementos da teoria marxista são reelaborados por Laclau e Mouffe na transição para o pós-marxismo. Para tanto, foram identificados conceitos e formas discursivas oriundos do pensamento marxista, que são reformulados pelos autores para compor o novo enfoque, a partir de uma análise das principais obras em que os autores apresentam sua abordagem 
pós-marxista: Hegemonia e estratégia socialista (2010 [1985]) e Novas reflexões sobre a revolução de nosso tempo (1993).

Em Posmarxismo sin pedido de disculpas, Laclau e Mouffe (1993) afirmam que as noções de materialismo, antagonismo e hegemonia constituem os três pontos fundamentais da teoria marxista que devem ser desenvolvidos para se pensar um novo enfoque de análise social e política. Nesse sentido, analisaremos de que maneira tais noções são reformuladas pelos autores na construção de um aparato teórico-político que busca superar os "apriorismos" essencialistas do marxismo e apreender alguns problemas cruciais à compreensão da sociedade contemporânea - como a emergência de novos antagonismos sociais.

A partir dessa análise, é possível questionar em que medida o enfoque teórico desenvolvido por Laclau e Mouffe pode ser apreendido a partir do problema da relação entre clássicos e contemporâneos na teoria social e qual a pertinência de se recorrer à desconstrução como meio de interpelação dos autores clássicos. Ademais, na esteira da discussão sobre a relação entre clássicos e contemporâneos, é importante discutir em que medida seu esforço de restauração da tradição marxista apresenta um compromisso "com a busca contemporânea de conhecimento científico” (Alexander, 1999, p. 24).

Considerada quase uma "obsessão" da Sociologia, a releitura e reinterpretação dos autores clássicos constitui uma das principais atividades observadas no interior da disciplina, através da qual os sociólogos buscam aperfeiçoar conceitos e desenvolver novas teorias ${ }^{5}$. Desde Talcott Parsons, os principais sociólogos contemporâneos se destacaram por um esforço em construir teorias sociológicas que visam reunir as principais contribuições dos autores clássicos e, ao mesmo tempo, responder às questões e problemas fundamentais enfrentados pela disciplina. Esse é o caso de Anthony Giddens, Jurgen Habermas e Pierre Bourdieu - para citar apenas os mais consagrados em todo o mundo, cuja posição parece reivindicar também o status de "clássicos" da sociologia.

No entanto, diferentemente do percurso teórico observado entre esses autores, Laclau e Mouffe não buscam resgatar as principais contribuições dos

\footnotetext{
${ }^{5}$ Para uma discussão sobre a importância dos clássicos na ciência social cf. Alexander (1999).
} 
clássicos da sociologia, nem alcançar uma posição central no campo sociológico propriamente dito. Os autores travam um diálogo crítico principalmente com a tradição marxista e, em particular, com o pensamento de Karl Marx, com o intuito de construir uma teoria social capaz de apreender as novas configurações do capitalismo tardio e de impulsionar intervenções na realidade a partir de um projeto político de esquerda - muito embora eles também apresentem seu enfoque teórico como uma alternativa àqueles desenvolvidos por Habermas, Giddens, dentre outros, destacando seus respectivos limites, sobretudo com relação à sua análise sobre o processo de modernização vigente nas sociedades contemporâneas e à proposição de projetos políticos para tais sociedades.

\section{Do materialismo à Teoria do Discurso}

0 primeiro ponto trabalhado pelos autores é de natureza filosófica e se relaciona com o caráter parcial do materialismo de Marx. Segundo Laclau e Mouffe (1993), Marx dá um importante passo no desenvolvimento do materialismo ao afirmar que as ideias não constituem um mundo fechado que se auto reproduz, mas estão enraizadas no conjunto das relações materiais da sociedade. 0 materialismo está ligado ao seu relacionismo radical, que permite acentuar o caráter relacional, histórico e precário do mundo das formas. De acordo com os autores, o mérito do materialismo de Marx foi mostrar que o sentido de toda realidade humana deriva de um mundo de relações sociais muito mais vasto do que se havia percebido até então. Contudo, o seu movimento em uma direção relacionista é débil, uma vez que Marx apenas inverteria a lógica hegeliana.

O que distingue o idealismo do materialismo é afirmação idealista do caráter em última instância conceitual do real. 0 idealismo aparece de maneira mais desenvolvida e coerente na obra de Hegel, que afirma que todo real é racional. Desse modo, o idealismo, no sentido que se opõe ao materialismo, e não ao realismo, não afirma que não existam objetos externos à mente, mas que a natureza mais profunda destes objetos é idêntica à da mente, isto é, que é em última instância pensamento. Mesmo Platão e Aristóteles identificaram a realidade última de um objeto com a sua forma, isto é, com algo universal e conceitual, que 
pode ser também aplicado a outros objetos. O elemento que não pode ser subsumido a uma categoria universal é considerado incognoscível e irracional. Os filósofos antigos denominavam este último resíduo irredutível ao pensamento como matéria. E foi precisamente esse resíduo que foi eliminado pelo idealismo absoluto de Hegel, que afirmou a racionalidade completa do real. A forma se torna, ao mesmo tempo, o princípio organizador da mente e a realidade última do objeto (Laclau e Mouffe, 1993, p. 121).

Nesse sentido, os autores afirmam que muito do que se denominou como “materialismo" é em boa parte idealista. A obra de Marx constituiria apenas o começo de um movimento na direção do materialismo, na medida em que ele permanece, em certo sentido, claramente dentro do campo idealista, ou seja, dentro da afirmação final da racionalidade do real. Ao afirmar que a lei de movimento da história não é determinada pelo curso das ideias na mente dos homens, mas pela contradição entre as forças produtivas e as relações de produção, Marx não supera o idealismo, uma vez que o que é idealista é a ideia de que há uma lei final de movimento que pode ser conceitualmente apreendida. Nas suas palavras,

\footnotetext{
"afirmar a transparência final do real ao conceito é o mesmo que afirmar que o real é 'forma'”. Por esta razão, as tendências mais deterministas dentro do marxismo são também as mais idealistas, já que baseiam suas análises e predições em leis inexoráveis que não são imediatamente legíveis na superfície da vida histórica; elas devem basear-se na lógica interna de um modelo conceitual fechado e transformar esse modelo na essência (conceitual) do real" (Laclau e Mouffe, 1993, p. 122. Tradução nossa).
}

Os autores ressaltam que todo movimento que busca se distanciar do idealismo deve debilitar sistematicamente as pretensões da forma de esgotar a realidade do objeto, ou seja, das pretensões que Heidegger e Derrida chamaram de “metafísica da presença”. A perspectiva desconstrucionista não separa o pensamento da coisa, mas a forma da ausência de forma ou do indefinido, em cada um deles. Em $A$ estrutura, o signo e o jogo no discurso das Ciências Humanas, Derrida (2002) critica a noção de uma estrutura fechada em si mesma como centro das relações sociais. Segundo ele, a atribuição de um centro à estrutura permite relacioná-la a um ponto de presença, a uma origem fixa, que possibilita orientar e 
organizar a estrutura e, ao mesmo tempo, limitar o jogo de significações dentro dela. A definição de uma estrutura centrada é considerada contraditoriamente coerente, na medida em que, por um lado, ela representa a própria coerência e condição da episteme e da filosofia como ciência, mas, por outro lado, o centro, que é responsável por reger a estrutura, escapa ao processo de estruturação. 0 centro se situa na estrutura e fora da estrutura.

Nessa perspectiva, o postulado de um centro último é motivado pelo desejo de dominar a ansiedade que acompanha um certo modo de ser implicado no processo de estruturação. Essa ansiedade é dominada a partir de um centro privilegiado, que pressupõe a noção de um jogo fundado, constituído a partir de uma imobilidade fundadora e de uma certeza tranquilizadora, ela mesma subtraída ao jogo. O centro que permite a supressão de um jogo de sentido está, ele mesmo, fora do jogo. Desse modo, o centro é invocado como uma presença plena e fora de jogo. É justamente o desejo sempre não realizado de um centro que permite o surgimento de deslocamentos sem fim e substituições do centro. Entretanto, um centro que não é nunca ele mesmo, mas é sempre deslocado e substituído não pode ser pensado em termos de uma presença plena.

Derrida (2002, p. 232) denuncia a metafísica da presença que perpassa todo o pensamento ocidental e afirma que é necessário pensar a ausência de um centro. O centro não pode ser pensado na forma de um sendo presente, nem como tendo um lugar natural, um local fixado. Para ele, o centro constitui uma função, uma espécie de não-lugar no qual se fazem indefinidamente substituições de signos. 0 autor afirma que na ausência de um centro ou de origem, tudo se torna discurso. 0 discurso é definido como um sistema de diferenças dentro do qual o jogo de significação se estende infinitamente devido à ausência de um significado transcendental. Segundo Torfing (1999, p. 40), a noção de discurso de Derrida permite enfatizar o momento da não fixidez na construção do sentido. 0 discurso pode ser definido como uma estrutura descentrada na qual o sentido é constantemente negociado e construído.

Fortemente influenciados pelo pensamento de Derrida, Laclau e Mouffe (1993, p. 123) tentam reformular o materialismo de uma maneira radical, 
aprofundando o caráter relacional do pensamento de Marx, a partir da Teoria do Discurso. Esta tentativa constitui um primeiro sentido do seu pós-marxismo. A noção de discurso torna-se central neste novo enfoque porque ressalta que toda configuração social é significativa e que o sentido de um evento social não está dado de antemão, não the é inerente e só aparece num sistema de relações. Esse sistema de relações que dá sentido ao objeto é o discurso ${ }^{6}$. A concepção do espaço social como espaço discursivo e a ideia de que, apesar de o objeto possuir uma existência física independente, o seu sentido só se constitui no interior das relações sociais conduz à noção de que o "ser” dos objetos é diferente de sua “existência” e que os objetos nunca se dão como mera "existência”, mas sempre articulados dentro de totalidades discursivas. Como nenhuma totalidade discursiva é inteiramente autocontida, uma vez que há sempre um exterior que the impede de se constituir plenamente, a forma e a essência dos objetos estão penetradas por uma instabilidade e precariedade básicas, que constituem sua mais essencial possibilidade. É neste sentido que a Teoria do Discurso se constitui como ponto de partida para abandonar o idealismo e reformular o materialismo.

Os autores estendem a noção da linguagem de Saussure e Wittgenstein como um sistema de diferenças em que a identidade dos objetos é puramente relacional para o conjunto das estruturas sociais. Isto não significa que tudo seja linguagem, no sentido restritivo de fala ou escrita, mas que a estrutura relacional ou diferencial da linguagem caracteriza todas as estruturas significativas. Portanto, se toda identidade é diferencial, o sistema de diferenças não pode ser fechado, mas é exposto à ação de estruturas discursivas externas, que tornam a identidade instável. Essa noção de identidade impossibilita atribuir ao "ser" dos objetos uma essência fixa e permite o debilitamento da forma. Segundo os autores, “os homens constroem socialmente seu mundo, e é através dessa construção - sempre precária e incompleta - que eles dão às coisas seu ser" (Laclau e Mouffe, 1993, p. 124. Tradução nossa).

\footnotetext{
${ }^{6}$ A concepção de formação discursiva de Laclau e Mouffe tem uma coerência interna muito semelhante à elaborada por Foucault (1999) - de regularidade na dispersão - mas distancia-se desta última na distinção que é feita pelo autor entre práticas discursivas e extradiscursivas. Para os autores, todo objeto se constitui como objeto do discurso e nenhum objeto se encontra fora de uma superfície discursiva de emergência.
} 
Nesse sentido, surge uma terceira oposição entre idealismo e materialismo, em que um mundo de formas fixas que constituiria a realidade última do objeto, pressuposto do idealismo, é colocado em xeque pelo caráter relacional, histórico e precário do mundo das formas, que constitui e caracteriza o materialismo de Laclau e Mouffe. Os autores defendem que não há possibilidade de eliminar o hiato entre "realidade" e "existência". Desse modo, idealismo e materialismo clássicos podem ser considerados como duas variantes de um essencialismo ou todo essencialismo pode ser considerado idealismo, uma vez que reduz o real ao conceito. 0 materialismo é apresentado como uma categoria que engloba as várias tentativas de romper com esta subordinação. Nessa perspectiva, o esforço de Marx constitui apenas um momento de transição na superação do idealismo. Por um lado, os autores afirmam que um possível modo de entender a incorporação das ideias nas condições materiais da sociedade seria em termos de totalidades discursivas. O "Estado" ou as "ideias" não seriam, portanto, entidades auto constituídas, mas "diferenças" no sentido saussuriano, que constituem suas identidades relacionalmente com outras diferenças, como "forças produtivas", "relações de produção" etc. Segundo Laclau e Mouffe (1993, p. 125. Tradução nossa),

\footnotetext{
“o progresso 'materialista' de Marx seria ter mostrado que a área das diferenças sociais que constitui as totalidades significantes é muito mais ampla e profunda do que até então se havia suposto; que a reprodução material da sociedade é também uma parte das totalidades discursivas que determinam o sentido das formas mais 'sublimes' da vida política e intelectual” (Grifo dos autores).
}

Esse modo de interpretar o materialismo de Marx permite superar os problemas relacionados à relação base/superestrutura, pois se as identidades são puramente diferenciais, a presença de cada uma delas envolve a presença de outras, de modo que não é possível desenvolver nenhuma teoria causal acerca da eficácia de um elemento sobre os outros. Por outro lado, o relacionismo radical de Marx é traduzido imediatamente em termos idealistas, quando ele afirma que não é a consciência do homem que determina seu ser, mas o ser social determina a consciência. Tal afirmação pode ser lida como a reintegração da consciência à existência e como a existência social determina a consciência, esta última não 
pode ser vista como parte da existência social. Para Laclau e Mouffe (1993, p. 126), toda tentativa de superar o hiato existente entre realidade e existência, bem como de identificar a essência do ser, seja no âmbito das ideias ou no âmbito da vida material, constitui uma forma de essencialismo e, portanto, de idealismo. 0 pósmarxismo aprofunda o momento relacional que Marx não poderia desenvolver mais a partir de uma matriz hegeliana e, em todo caso, própria do século XIX. É só a partir da contribuição da psicanálise, que afirma que a ação do inconsciente torna toda significação ambígua, da linguística estrutural e da transformação do pensamento que solapou toda forma de essencialismo que é possível reformular o programa materialista de um modo muito mais radical do que seria possível para Marx.

$\mathrm{Na}$ transição para o pós-marxismo, os autores assumem uma perspectiva ontológica distinta, em que rejeitam o modelo de sociedade como totalidade que determina todo arranjo estrutural através de suas leis internas. Eles enfatizam o caráter aberto e incompleto do social e a contingência como constitutiva de todo contexto estrutural de interação social. A Teoria do Discurso desenvolvida pelos autores permite destacar a radical historicidade do ser, o caráter puramente humano da verdade e a concepção do mundo como uma construção puramente social dos homens, que não está fundada em nenhuma necessidade externa a ela mesma.

\section{Do antagonismo à impossibilidade de toda objetividade}

A afirmação de que o desenvolvimento histórico pode ser racionalmente apreendido e é, portanto, forma, também impede o desenvolvimento de todas as implicações decorrentes da compreensão de Marx do papel da luta e da negatividade na constituição do social. Laclau e Mouffe (1993, p. 145) destacam que o grande mérito da teoria marxista foi $o$ de iluminar as tendências fundamentais do capitalismo, apontando os antagonismos gerados por este sistema. Entretanto, no mesmo momento em que a visão marxista da história se abre para uma compreensão mais profunda do papel do antagonismo na constituição das 
relações sociais, ela dá um passo atrás e tenta integrar essa compreensão a uma teoria da positividade do social.

Laclau (1993, p. 22) destaca que, enquanto no Manifesto Comunista, Marx afirma que a luta de classes é o motor da história, no Prefácio à Contribuição à Crítica da Economia Política, a luta de classes está inteiramente ausente e a história é determinada pela contradição entre as forças produtivas e as relações de produção. A teoria de Marx não integra logicamente estes dois momentos e atribui à contradição forças produtivas/ relações de produção a determinação em última instância da mudança social. A dualidade forças produtivas/relações de produção seria uma contradição sem antagonismo. Essa dualidade é uma contradição no sentido estrito do termo, na medida em que a continuidade da expansão das forças produtiva além de certo ponto do desenvolvimento das relações de produção constitui uma impossibilidade lógica, que se traduz no colapso mecânico do sistema. Mas da impossibilidade de se expandir o sistema econômico além de certo ponto e do seu consequente colapso não se segue que esse colapso resulte de um enfrentamento entre grupos. O Prefácio pressupõe um período de revolução social e o caráter antagônico das relações de produção, mas não integra a luta de classes ao modelo geral da mudança histórica. A luta de classes constitui um antagonismo sem contradição.

A afirmação do caráter racional e positivo da história depende da redução da luta de classes a um momento interno do desenvolvimento endógeno das forças produtivas, uma vez que considerar esses dois momentos como independentes implicaria admitir que a história depende de uma relação contingente de poder entre os dois momentos. Como consequência, a unidade dialética da história seria colocada em questão e as relações entre luta de classes e desenvolvimento das forças produtivas deixariam de estar fixadas a priori. Não haveria possibilidade de considerar a contradição entre forças produtivas e relações de produção como fundamento da história, posto que esta última teria sempre algo constitutivamente exterior a si mesma (Laclau, 1993, p. 23).

Laclau (1993, p. 24) afirma que para garantir o caráter racional da história, a teoria marxista deve mostrar que o antagonismo inerente às relações de 
produção é uma contradição e que essa contradição é inerente às relações de produção. Isso porque a forma dialética da contradição assegura que o antagonismo seja concebido como movimento interno do conceito e não como relação contingente de poder entre os seus dois polos. A consideração de que as relações de produção são intrinsecamente antagônicas garante que a forma "racional" do processo histórico não tenha nada exterior a si mesmo; nada que não possa ser reduzido à manifestação de seu desenvolvimento endógeno. Contudo, o antagonismo entre trabalho assalariado e capital não implica necessariamente contradição, uma vez que esta última se dá no campo da lógica e, o antagonismo constitui-se no campo discursivo. Enquanto a contradição hegeliana sugere que o movimento dialético do conceito determina suas formas subsequentes, a concepção de antagonismo de Laclau e Mouffe $(1993,2010)$ tenta superar todo pressuposto idealista e toda estrutura predada no nível material. Para os autores, o antagonismo é uma construção discursiva e a sua resolução depende inteiramente de uma história factual e contingente.

O antagonismo foi concebido pelo marxismo da Segunda Internacional como inerente à forma das relações de produção, como alternativa para se pensar a relação entre o colapso automático do capitalismo e a ação da classe operária em sua derrocada. Se o antagonismo não conduz por si mesmo à abolição das relações de produção, já que este desfecho histórico depende do desenvolvimento das forças produtivas, ele pode fazê-lo na medida em que a expansão das forças produtivas tenha tornado as relações de produção obsoletas. Entretanto, Laclau (1993, p. 25) afirma que o fundamento teórico dessa relação depende da redução dos agentes sociais concretos às categorias econômicas de comprador e vendedor da força de trabalho.

Para mostrar que as relações de produção são intrinsecamente antagônicas seria necessário demonstrar que o antagonismo surge logicamente da relação entre essas categorias. Mas é só se o operário resiste à extração de mais valia que a relação passa a ser antagônica; e não há nada na categoria vendedor da força de trabalho que sugira que essa resistência é uma conclusão lógica. O conflito não é interno às relações de produção, nas quais o trabalhador só conta como vendedor 
da força de trabalho, mas se estabelece entre as relações de produção e a identidade do trabalhador que é exterior às mesmas.

Laclau e Mouffe (1993) consideram este exterior constitutivo inerente a toda relação antagônica. Segundo eles, o modo e a intensidade do antagonismo dependerão do modo que o agente social está constituído fora das relações de produção. A percepção por parte dos operários de seu lugar no mundo depende de sua participação em uma variedade de esferas da sociedade e de certa consciência dos seus direitos. É possível compreender a dificuldade da teoria marxista de integrar estas duas lógicas da história, uma fundada na contradição forças produtivas/ relações de produção e a outra na centralidade da luta de classes, e a constante tensão entre ambas na história do marxismo. A concepção do caráter constitutivo do antagonismo implica a negação do desenvolvimento das forças produtivas como fundamento racional da história, ou mesmo da história como estrutura inteligível que pode ser apreendida racionalmente, uma vez que os antagonismos são considerados como resultantes de relações de poder entre forças que não podem ser submetidas a nenhum tipo de lógica unificada (Laclau, 1993, p. 26).

Partindo dessa crítica, o pós-marxismo de Laclau e Mouffe radicaliza a noção de antagonismo da teoria marxista, buscando encarar todas as consequências dessa concepção. Uma delas é o reconhecimento da contingência que penetra radicalmente a identidade dos agentes sociais. Como a objetividade é sempre ameaçada por um exterior constitutivo, é no nível da história factual e contingente onde se revelam as condições de qualquer objetividade que possa existir. Além disso, a relação antagônica não surge de identidades plenas, mas da impossibilidade de constituição das mesmas. A presença de uma força antagônica impede que uma identidade se constitua plenamente. A força antagônica, por sua vez, também não possui uma identidade plena (Laclau, 1993, p. 39).

A tarefa de retomar e aprofundar a discussão sobre o papel fundamental do antagonismo se encontra no centro do enfoque pós-marxista. Em primeiro lugar, porque os efeitos deslocatórios do capitalismo são bem mais profundos atualmente do que no tempo de Marx. Apesar disso, Laclau e Mouffe (2010, p. 14) afirmam que 
há uma tendência de excluir a noção de antagonismo tanto dos discursos políticos da esquerda como ao nível da teoria. O desaparecimento do antagonismo do discurso da esquerda é decorrente do colapso do modelo soviético e do descrédito da própria ideia de socialismo. Segundo os autores, com a queda do comunismo na URSS, a social-democracia entrou em crise, em vez de ser revitalizada, e não houve uma reformulação do projeto socialista, mas o triunfo do neoliberalismo, cuja hegemonia passou a ser tão generalizada que influenciou a própria identidade da esquerda. A tese básica sustentada pelo que se convencionou chamar de "terceira via" é que,

\footnotetext{
"a queda do comunismo e as transformações socioeconômicas ligadas ao advento de uma sociedade informática e aos processos de globalização conduziram à desaparição dos antagonismos sociais. Uma política sem fronteiras resultaria agora possível - uma 'win-win politics'” -, fundada em soluções que favoreceriam a todo mundo. Isto significa que a política já não se estruturaria mais em torno da divisão social e que os problemas políticos tinham passado a ser meramente técnicos" (Laclau e Mouffe, 2010, p. 15. Tradução nossa).
}

Ulrich Beck e Anthony Giddens se apresentam como os teóricos dessa nova política, segundo a qual vivemos na era da modernização reflexiva, em que a sociedade industrial passaria por um processo de (auto)destruição criativa, cujo sujeito não é a revolução nem a crise do capitalismo, tampouco a luta de classes, mas a vitória da modernização ocidental. Na nova forma social, o modelo adversarial da política perde toda a sua validade. A política deve se concentrar nos problemas da "vida", ser geradora e permitir que os distintos grupos realizem os seus objetivos. A democracia é concebida como forma de um diálogo em que as controvérsias são resolvidas escutando-se a uns e outros.

0 enfoque pós-marxista se distancia dessa perspectiva, que também pode ser observada em Habermas e em seu projeto de democracia radical, posto que para Laclau e Mouffe (2010, p. 16) a radicalização da democracia nunca tem lugar em um terreno neutro. A concepção da democracia como uma simples competição se fundamenta na ideia da crescente racionalidade dos agentes e sua capacidade de construir um consenso através da razão, eliminando, dessa forma, os antagonismos. Tal concepção é decorrente do abandono do modelo jacobino "amigo/inimigo da política" e da adoção do modelo liberal dominante nas ciências 
humanas e na política. Entretanto, os autores destacam que essa visão do processo democrático impossibilita a apreensão da estrutura das relações de poder e a tentativa de transformar a presente ordem hegemônica.

O desaparecimento do antagonismo do discurso político da esquerda é percebido como a principal fonte de suas dificuldades presentes, de modo que a elaboração de um projeto hegemônico de esquerda requer a criação de novas fronteiras políticas e não a sua desaparição. Para os autores, não pode haver política radical sem a identificação de um adversário e, para tanto, faz-se necessário reconhecer o caráter inerradicável do antagonismo. Por outro lado, o antagonismo fecha toda possibilidade de uma reconciliação final e de um nós plenamente inclusivo; a ideia de uma esfera pública sem exclusões, dominada pela argumentação racional, constitui uma impossibilidade conceitual. O conflito e a divisão são necessários mesmo à formação de uma política democrática e plural. Nesse sentido, o projeto democrático deve reconhecer que não há possibilidade de uma resolução final e que toda forma de consenso é resultante de uma articulação hegemônica (Laclau e Mouffe, 2010, p. 18).

Com o abandono de uma concepção racionalista e objetivista da história, os autores reformulam e radicalizam a negatividade do social, fundamentada na noção de conflito como motor da história, própria da teoria marxista, para pensar o antagonismo como constitutivo do social e como possibilidade de transformação social.

A publicação de Hegemonia e Estratégia Socialista, em 1985, suscitou um intenso debate, no qual a perspectiva teórica de Laclau e Mouffe foi questionada à luz de questões centrais da teoria social contemporânea, o que possibilitou uma rica discussão e a oportunidade de os autores reformularem alguns conceitos do seu enfoque pós-marxista. Nesse contexto, é importante destacar a crítica de Slavoj Žižek à concepção de sujeito encontrada na teoria de Laclau e Mouffe neste primeiro momento, que reflete a influência do pós-estruturalismo e mesmo do estruturalismo, caracterizados pela rejeição do sujeito autônomo e pela celebração anti-humanista da morte do sujeito. 
Apesar de enfatizar a importância da história, do poder e da vida cotidiana na sua conceituação do processo de subjetivação, o pós-estruturalismo desencoraja o desenvolvimento de uma teoria do sujeito. A mesma tendência pode ser observada nas várias versões de pós-marxismo, que buscam preencher o espaço vazio deixado pelo abandono da ideia de uma classe universal com referências otimistas à proliferação dos novos movimentos sociais que emergem no âmbito das políticas de gênero, raciais etc. Assim como no pós-estruturalismo, o foco pósmarxista tem sido na formação de diversas formas de subjetividades políticas e não na elaboração de uma teoria do sujeito (Torfing, 1999, p 56).

Žižek tenta suprir essa falha do pós-estruturalismo e do pós-marxismo em conceituar o sujeito antes do processo de subjetivação, a partir da concepção lacaniana de sujeito. Em $O$ sublime objeto da Ideologia (1992), o autor explica a diferença entre a posição pós-estruturalista e a posição lacaniana. No primeiro caso, o sujeito é reduzido à subjetivação, concebido como efeito de um processo fundamentalmente não subjetivo. 0 foco pós-estruturalista seria os diferentes modos de "experienciar" individuais, deixando de lado suas posições como sujeitos e agentes do processo histórico. Com relação à noção lacaniana, Žižek afirma que numa abstração que subtraia toda a riqueza dos diferentes modos de subjetivação e toda plenitude da experiência presente no modo que os indivíduos estão vivendo suas posições de sujeito, o que permanece é um lugar vazio, que foi preenchido por toda essa riqueza. Esse lugar vazio, que indica uma falta na estrutura simbólica, é o sujeito. Portanto, o sujeito é estritamente oposto ao efeito da subjetivação, já que este último mascara justamente a falta na estrutura que constitui o sujeito (Torfing, 1999, p. 57).

Para Žižek, os autores falharam na teorização da falta constitutiva do sujeito antes da sua subjetivação no nível das posições de sujeito. Segundo o autor, a identidade negada pela presença de uma força antagônica é sempre já negada, de modo que o antagonismo constitui uma negação da negação. 0 antagonismo social não nega uma identidade plenamente realizada, mas, ao contrário, nega um sujeito "rachado" que está tentando se estabelecer como identidade plena através de atos de identificação. A ideia de que com a eliminação da força antagônica seria 
possível constituir identidades plenas não passaria de um mecanismo ideológico (Torfing, 1999, p. 52).

Num momento posterior, a teoria do sujeito de Lacan assume um papel fundamental no enfoque pós-marxista de Laclau e Mouffe. Em Novas Reflexões sobre a Revolução do nosso tempo, Laclau (1993) aceita a crítica de Žižek e introduz a categoria de deslocamento no seu enfoque teórico para pensar o lugar do sujeito. O deslocamento resulta da disrupção de uma estrutura por forças antagônicas que operam fora dela. Como o exterior que desloca a estrutura não tem uma medida comum com o seu interior, não se trata de um momento necessário na autotransformação da estrutura, mas do fracasso na constituição plena desta última. O sujeito é resultante da impossibilidade da estrutura de se constituir plenamente. Segundo o autor, "o sujeito possui uma identidade estrutural falida" (Laclau, 1993, p. 60). Ele se autodetermina parcialmente, mas essa autodeterminação não expressa algo que o sujeito já é, mas a sua falta de ser, de modo que a autodeterminação procede de atos de identificação.

O antagonismo implica a presença de um "exterior constitutivo", que bloqueia a identidade do "interior" e que é, ao mesmo tempo, a condição de sua constituição. A relação entre bloqueio e afirmação simultânea de uma identidade é que o autor denomina como contingência, que introduz um elemento de radical indicibilidade em toda estrutura objetiva. A noção de indicibilidade estrutural implica que toda decisão que desenvolve uma de suas possibilidades será contingente, ou seja, externa à estrutura, no sentido de que, apesar de ser possível a partir de uma estrutura, não é determinada por ela. 0 agente dessa decisão contingente não é nem totalmente externo à estrutura, nem totalmente interno a esta última, posto que se autonomiza parcialmente com relação a ela, já que constitui o lócus de uma decisão que a estrutura não determina. As decisões tomadas a partir da estrutura não apenas transformam e subvertem esta última, como também transformam a própria identidade dos agentes.

Laclau (1993, p. 47) afirma que o sujeito é justamente a distância entre a estrutura indecidível e a decisão. Essa decisão tem um caráter fundante tão 
primário quanto o da estrutura a partir da qual é tomada. Se a decisão tem lugar a partir de uma estrutura indecidível, a sua tomada implica a repressão de decisões alternativas, ou seja, a objetividade resultante de uma decisão se constitui como relação de poder. Esses elementos são fundamentais para se compreender a especificidade do político e sua primazia sobre o social no enfoque pós-marxista de Laclau e Mouffe.

Mais recentemente, Daniel de Mendonça (2003, p. 136) destacou que a noção filosófica de antagonismo tem sido empregada, por vezes, de maneira genérica e imprecisa por Laclau e Mouffe. Por um lado, o antagonismo é responsável pela impossibilidade de fechamento completo dos sentidos de um discurso, exemplificado, em Hegemonia e Estratégia Socialista, pela oposição entre povo e antigo regime, entre duas formas de sociedade absolutamente distintas, em que uma impede a plena constituição da outra. Por outro lado, essa noção também aparece no mesmo texto para caracterizar os novos movimentos sociais constituídos para reivindicar suas demandas identitárias no contexto de um Estado democrático que, a rigor, não nega suas existências. Contudo, o autor afirma que só no primeiro caso é possível falar de antagonismo - que pressupõe que os elementos antagônicos não possuem conteúdos comuns -, haja vista que no segundo caso não se observa dois discursos antagônicos, mas apenas identidades que reivindicam direitos a um ente político universalizante por excelência: 0 Estado.

Posteriormente, Chantal Mouffe conseguiu solucionar esta ambiguidade ao introduzir a noção de agonismo em seu enfoque teórico. A diferença fundamental entre o antagonismo e o agonismo é que este último pressupõe não apenas a disputa entre formações discursivas, mas uma medida comum entre elas, ou seja, a existência de regras que fazem com que os adversários partam para a luta de um ponto comum, não com o fim de destruir o oponente, mas de legitimar um discurso em detrimento do outro. Enquanto predomina na teoria social contemporânea certo entusiasmo com a possibilidade de uma forma consensual de democracia, decorrente da influência do pensamento liberal, ancorado no individualismo e no progresso da racionalidade, Mouffe $(2009$, p. 10) destaca que a negação da dimensão antagônica constitutiva do político tem consequências para a formulação 
de uma política democrática. Tal negação impede a compreensão do que está em jogo na política democrática e na dinâmica de constituição das identidades coletivas, o que explicaria a inabilidade da teoria democrática em captar a natureza dos fenômenos políticos de massa ou de fenômenos como o nacionalismo.

A concepção da política democrática em termos de consenso e reconciliação não é apenas conceitualmente errônea, mas pode implicar em riscos políticos, uma vez que ela impede a criação de uma esfera pública adequada à luta agonista, onde seria possível confrontar diferentes projetos políticos hegemônicos. Segundo Mouffe (2009, p. 11), tal concepção estaria na raiz de muitos dos problemas que enfrentam as instituições democráticas, contribuindo para exacerbar o potencial antagônico que existe na sociedade, em que o surgimento de antagonismos coloca em xeque os próprios parâmetros da ordem existente. Ao reconhecer a dimensão constitutiva do conflito social e do antagonismo, a autora considera que o principal desafio à política democrática implica justamente em transformar relações antagônicas em agônicas, superando a relação entre inimigos para uma relação entre adversários. Embora os adversários não sejam percebidos como meros competidores, a política democrática deve fornecer os mecanismos para uma relação "nós/eles" - fundamental à constituição de identidades políticas - na qual esse embate não se orienta para a eliminação do "eles". 


\section{A nova abordagem da hegemonia}

A afirmação do caráter constitutivo do antagonismo conduz à centralidade da noção de hegemonia no pós-marxismo de Laclau e Mouffe, que constitui o terceiro ponto da tradição marxista a ser reformulado. Esse ponto é de natureza tanto teórica quanto política e se relaciona com a sua concepção de socialismo e o lugar que este último assume no projeto político dos autores. Em Hegemonia e Estratégia Socialista, Laclau e Mouffe (2010, p. 31) fazem uma genealogia do conceito de hegemonia e destacam que ele surgiu no seio da tradição marxista para preencher a lacuna deixada pela categoria de "necessidade histórica", que havia sido a pedra angular do marxismo da Segunda Internacional, e para responder às crescentes situações de contingência decorrentes das transformações da sociedade capitalista7.

Para os autores, o pensamento de Gramsci representou um verdadeiro divisor de águas na tradição marxista, uma vez que a sua teorização da hegemonia constitui uma das tentativas mais elaboradas de responder à chamada "crise do marxismo", adequando as categorias marxistas às transformações da sociedade capitalista, caracterizadas pela fragmentação das classes sociais e inúmeras situações de contingência. Gramsci amplia o terreno atribuído à recomposição política e à hegemonia para além da aliança de classes, afirmando a necessidade de uma liderança intelectual e moral que permita aos grupos sociais se distanciarem de uma postura corporativista e se unirem aos interesses de outros grupos. Desse modo, ele dá visibilidade à especificidade relacional do vínculo hegemônico, até então escamoteada, mostrando que a identidade dos agentes não é a mesma após o estabelecimento de uma articulação hegemônica.

Contudo, se o seu pensamento permite pensar a identidade dos diversos elementos sociais como relacional, na medida em que esta é alcançada através da

\footnotetext{
${ }^{7}$ Os autores afirmam que o conceito de hegemonia surge na social-democracia russa para descrever as limitações da burguesia, insuficientemente desenvolvida, em exercer suas próprias tarefas, o que obrigou a classe operária a sair de si mesma e assumir tarefas que não the eram próprias. Entretanto, nesta perspectiva, o conceito de hegemonia corresponde a uma relação anômala, já que há uma separação entre a natureza de classe de uma tarefa e o agente histórico que a executa (Laclau e Mouffe, 2010, p. 31).
} 
ação das práticas articulatórias, ele sustenta dois princípios que se formam na infraestrutura econômica e não estão sujeitos à lógica da hegemonia. Trata-se da unicidade do princípio unificante e seu caráter necessário de classe que não são o resultado contingente da luta hegemônica, mas o marco estrutural necessário dentro do qual toda luta hegemônica tem lugar. A hegemonia da classe não seria inteiramente prática e resultante da luta política, mas teria em última instância um fundamento ontológico (Laclau e Mouffe, 2010, p. 100).

Laclau e Mouffe (2010, p. 104) afirmam, portanto, que há, no pensamento de Gramsci, um último núcleo essencialista, que põe um limite à lógica desconstrutiva da hegemonia, uma vez que a economia não está sujeita à lógica hegemônica. Os autores desenvolvem uma nova abordagem da hegemonia, enfatizando o momento da articulação e o caráter aberto e incompleto do social como pré-condição de toda prática hegemônica. Assim como em Gramsci, os autores consideram que nenhuma lógica hegemônica consegue dar conta da totalidade do social, pois isso produziria uma nova sutura e o próprio conceito de hegemonia se autoeliminaria.

Outra condição ao estabelecimento de um vínculo hegemônico é a indicibilidade estrutural, que define a ausência de uma lei imanente ou necessidade lógica. As identidades sociais são concebidas como relacionais, instáveis e historicamente constituídas. Diante da ausência de uma essência das identidades e de um centro que determine todo tipo de arranjo estrutural, a noção de discurso se torna central nessa abordagem, pois apesar da impossibilidade de fixação de um sentido, o social só existe como esforço de produzir este objeto impossível, através de fixações parciais de sentido (pontos nodais). 0 discurso se constitui com o intuito de dominar o campo da discursividade, de deter o fluxo das diferenças e constituir um centro (Laclau e Mouffe, 2010, p. 154).

O antagonismo também constitui uma pré-condição ao estabelecimento de uma relação hegemônica. Além da dimensão de negação da identidade e de toda objetividade, o antagonismo é importante para a constituição de uma universalidade hegemônica, em que uma particularidade assume a representação de uma universalidade inteiramente incomensurável com a primeira, 
transcendendo os seus próprios interesses para representar um grupo mais amplo. Isso é possível porque o grupo que se universaliza se apresenta como capaz de enfrentar uma determinada força antagônica, que impede a sociedade de se constituir plenamente. Para os autores, a universalidade hegemônica é a única que a comunidade política pode alcançar. Laclau (2000) ressalta que a particularidade, neste processo, não permanece enquanto tal, haja vista que é contaminada pela cadeia de equivalência formada pelos grupos sociais que deve representar.

Portanto, as condições necessárias ao estabelecimento de uma articulação hegemônica correspondem à presença de forças antagônicas e a instabilidade da fronteira que as separam, e são os fenômenos de equivalência e de fronteira que possibilitam a relação hegemônica. Na relação de equivalência há uma simplificação do espaço político em dois campos antagônicos e inconciliáveis, em que as diferenças mútuas são canceladas ou redefinidas devido à centralidade do que é idêntico a todas elas, mas que só pode ser constituído de maneira negativa. Já a lógica da diferença tende a expandir e complexificar o espaço político. Para Laclau e Mouffe (2010, p. 179), é justamente a dialética entre a lógica da diferença e a lógica da equivalência que possibilita a universalidade da relação hegemônica.

A nova abordagem da hegemonia constitui uma tentativa de apreender as mudanças sociais advindas com o capitalismo tardio e a emergência dos novos movimentos sociais, que produzem deslocamentos discursivos e não podem ser subsumidos à categoria de classe. Trata-se, portanto, de um enfoque teóricopolítico que tenta dar conta do sentido das lutas sociais e da nova configuração da política nas sociedades contemporâneas a partir de uma perspectiva que se contrapõe aos teóricos da modernização reflexiva, como Giddens, Beck e Lash (1997) ou mesmo à teorização da democracia radical elaborada por Habermas, que privilegiam a racionalidade comunicativa, a dimensão tecnológica ou dialógica, negligenciando as relações de poder.

Os autores afirmam também que sua teoria neogramsciana da hegemonia possibilita retomar a discussão sobre a estratégia socialista, que foi interrompida na tradição marxista desde Gramsci, como consequência do stalinismo. Contudo, 
essa nova abordagem implica uma reformulação da natureza política da tradição marxista e da sua noção de socialismo. Isso porque o essencialismo, que permeou o pensamento marxista e impediu o desenvolvimento de todas as implicações de algumas de suas categorias teóricas, também influenciou o seu imaginário político, impossibilitando a compreensão da pluralidade de lutas sociais que emergiam e a formulação de uma política radical.

Segundo Laclau e Mouffe (Ibid., p. 223), esta tendência essencialista conduziu à organização do discurso da esquerda em termos de uma lógica dos "pontos privilegiados apriorísticos", que operou em uma variedade de direções. Em primeiro lugar, esse discurso permite determinar, de modo apriorístico, os antagonismos fundamentais da sociedade e considera a classe operária como agente histórico privilegiado na luta pelo socialismo. Ele também permite determinar a priori os níveis sociais a partir dos quais é possível implementar mudanças na sociedade - estatismo, por um lado, economicismo, por outro. Por fim, o conceito clássico de revolução, ancorado no modelo jacobino, é considerado pelos autores como o último núcleo desta fixação essencialista. Esse conceito implica o caráter fundacional do fato revolucionário e a instituição de um ponto de concentração do poder a partir do qual a sociedade pode ser reorganizada "racionalmente". Na transição para o pós-marxismo, os autores abandonam a ideia marxista do proletariado como agente histórico privilegiado da mudança social, passo considerado fundamental para o reconhecimento da pluralidade dos antagonismos que tem lugar no campo do que se denominou arbitrariamente como lutas operárias e sua importância na construção de um novo imaginário político radicalmente libertário.

O pós-marxismo de Laclau e Mouffe (2010, p. 238) também recusa a ideia de pontos privilegiados de desencadeamento das mudanças históricas, tais como a Revolução, a Greve Geral ou a "evolução" como categoria que unifica o caráter acumulativo e irreversível dos avanços parciais. Segundo eles, o conceito de guerra de posição, no sentido gramsciano, indica precisamente a afirmação do caráter processual de toda transformação radical, de modo que o fato revolucionário é apenas um momento interno desse processo. A ideia de que a abolição da 
propriedade privada dos meios de produção geraria uma série de efeitos em cadeia e que conduziria à extinção de toda forma de subordinação também é questionada pelos autores, posto que não há vínculos essenciais que unam os distintos componentes do programa socialista. Além disso, a ideia de uma sociedade transparente, que implicaria o fim da política, também é abandonada no projeto pós-marxista, na medida em que os autores consideram o antagonismo constitutivo das relações sociais e que não há possibilidade de uma sociedade sem conflitos. Portanto, a política nunca poderá ser dissolvida.

O abandono de toda afirmação dogmática de uma "essência" do social e da pretensão de construir um discurso do universal, por um lado, e a afirmação da contingência e do caráter constitutivo da divisão social e do antagonismo, por outro, seriam as pré-condições para a formulação de um projeto hegemônico de esquerda. Essas são as bases do projeto político de democracia radical e plural proposto pelos autores. Em contraposição à hegemonia neoliberal, Laclau e Mouffe (2010, p. 197) propõem a radicalização da revolução democrática iniciada no século XVIII como alternativa para a esquerda, que visa estender seus ideais de igualdade e liberdade a esferas cada vez mais numerosas da sociedade e do Estado, através da expansão das cadeias de equivalência entre as distintas formas de opressão.

A proliferação dos antagonismos e o questionamento das relações de subordinação são percebidos por Laclau e Mouffe (2010, p. 207) como um momento de aprofundamento da revolução democrática. Os autores esboçam certo entusiasmo com alguns dos efeitos deslocatórios do capitalismo tardio, que possibilitaram novas formas culturais, ligadas ao crescimento dos meios de comunicação e ao desenvolvimento de uma "cultura democrática do consumo" que, segundo eles, possibilita a emergência de novas lutas e a resistência a antigas formas de subordinação.

O projeto de democracia radical e plural se ancora na ideologia liberal democrática, ressaltando que não se trata de romper com o liberalismo político, mas de aprofundar o seu momento democrático, o que possibilita o reconhecimento da emergência de um pluralismo de sujeitos e da abertura que 
uma democracia radicalizada requer $^{8}$. No entanto, Laclau e Mouffe (2010, p. 231) afirmam a necessidade de se romper com os pressupostos do liberalismo econômico, que concebem a economia como o domínio do "privado", sede de direitos naturais, dentro do qual os direitos democráticos não teriam nenhuma razão de serem aplicados. Os autores destacam que o terreno principal da luta especificamente anticapitalista depende da extensão dos direitos democráticos do domínio político clássico ao domínio da economia. É nesse sentido que o discurso socialista se insere no projeto de democracia radical, na medida em que ele desloca a crítica da desigualdade política até a crítica da desigualdade econômica, defendendo o direito do agente social à igualdade e à participação enquanto produtor e não somente enquanto cidadão. Esse deslocamento conduz ao questionamento de outras formas de subordinação e à reivindicação de novos direitos.

Portanto, todo projeto de democracia radicalizada pressupõe uma dimensão socialista, uma vez que é necessário abolir as relações capitalistas de produção que estão na base de numerosas relações de subordinação. Contudo, as reivindicações socialistas são percebidas como um momento interior à revolução democrática e só são inteligíveis a partir da lógica equivalencial que esta última instaura. 0 projeto político de Laclau e Mouffe (2010, p. 239) se ancora no descentramento e autonomia dos diversos discursos e lutas, bem como na multiplicação dos antagonismos e na construção de uma multiplicidade de espaços em que esses antagonismos possam se desenvolver. É nesse sentido que a concepção de socialismo do marxismo é reformulada para compor o aparato teórico e político do pós-marxismo.

Da ruptura com toda forma de apriorismo essencialista implícita em uma topografia do social se segue, necessariamente, o reconhecimento da impossibilidade de especificar a priori as superfícies de emergência dos antagonismos, uma vez que não há superfície que não seja constantemente subvertida pelos efeitos subdeterminantes de outras. Consequentemente, há um

\footnotetext{
${ }^{8}$ É importante destacar que muito embora os autores se ancorem no pensamento liberal para inserir o pluralismo em seu enfoque teórico-político, eles se distanciam da ênfase no individualismo e racionalismo que se hegemonizou mesmo entre os liberais mais progressistas. Para uma crítica do pensamento liberal a partir dessa perspectiva ver Chantal Mouffe (2009).
} 
constante deslocamento das lógicas sociais características de uma esfera até outras esferas.

A negação de uma "essência" do social, a afirmação da contingência e do caráter constitutivo do antagonismo também tem como consequência o reconhecimento dos limites do "princípio da equivalência democrática" e sua relação com a lógica da autonomia numa democracia radical e plural. Laclau e Mouffe (2010, p. 230) afirmam que nunca existe uma equivalência total, uma vez que toda equivalência está penetrada por uma precariedade constitutiva, derivada dos desníveis do social, que exige que ela seja complementada/limitada pela lógica da autonomia. Nesse sentido, os autores apontam que a demanda da igualdade não é suficiente para a construção de uma democracia radical e plural e deve ser balanceada pela demanda da liberdade. O princípio da separação de espaços é justamente a base da demanda de liberdade, onde reside o princípio do pluralismo que vincula a lógica do liberalismo ao projeto de democracia radicalizada.

A tentativa de ruptura com a perspectiva essencialista encontrada no discurso socialista, bem como o vínculo do projeto político de Laclau e Mouffe com o discurso liberal, reflete, em certo sentido, uma preocupação dos autores em evitar os riscos que condenaram as experiências socialistas do passado e que ameaçam todo projeto de democracia radicalizada. Como as referências a qualquer potência extra-social são abolidas com a revolução democrática, o totalitarismo consiste na possibilidade de surgimento de um poder puramente social, que se apresenta como total e se materializa em um órgão que se supõe representante do povo uno. A lógica totalitária nega a divisão social e o caráter constitutivo do antagonismo que havia se tornado visível com a democracia, sob o pretexto de representar a unidade do povo. Já a lógica da hegemonia como prática articulatória se institui como possibilidade de responder à ausência de um fundamento transcendental que unifica toda a ordem social e aos perigos do totalitarismo derivados da própria abertura do social, a partir da unificação de certos espaços políticos por meio de articulações hegemônicas. Contudo, Laclau e Mouffe (2010, p. 234) advertem que estas articulações são sempre parciais e submetidas à 
contestação, já que não existe uma garantia suprema e toda tentativa de estabelecer um fechamento definitivo do social conduz ao totalitarismo.

As articulações hegemônicas também permitem evitar outro perigo que ameaça a democracia e é exatamente oposto ao totalitarismo, a saber, a ausência de toda referência à unidade do social e de articulações que fixam parcialmente o seu sentido e que possibilitam, dessa forma, o estabelecimento de significações comuns aos diferentes sujeitos sociais. Laclau e Mouffe (2010, p. 235) afirmam que a ausência de toda articulação entre as relações sociais pode conduzir à implosão do social, à dissolução do tecido social a partir da destruição do quadro simbólico e à desaparição da política. Toda posição hegemônica se funda em um equilíbrio instável, uma vez que se constrói a partir da negatividade, mas só se consolida ao constituir a positividade do social.

\section{Considerações finais}

Laclau e Mouffe percebem no essencialismo que permeia a tradição marxista o grande obstáculo ao desenvolvimento de seus conceitos teóricos e à construção de um projeto político capaz de se contrapor à hegemonia neoliberal. Portanto, na transição para o pós-marxismo, os autores tentam superar toda forma de essencialismo, reformulando de maneira radical as formas discursivas do marxismo que, segundo eles, garantem sua permanência como ponto de referência da análise teórica e política das sociedades contemporâneas. O sentido da restauração da teoria marxista seria dado pelo prolongamento e reformulação de tais categorias.

No entanto, se essas categorias constituem o ponto de partida da reflexão dos autores, eles se distanciam radicalmente do pensamento marxista no desenvolvimento das mesmas, ancorando-se no pós-estruturalismo e na psicanálise. Desse modo, Laclau e Mouffe tentam superar o idealismo a partir de uma perspectiva materialista, mas, neste esforço, se fundamentam na crítica da “metafísica da presença” e tentam debilitar as pretensões da forma de esgotar a realidade do objeto. A perspectiva materialista de Laclau e Mouffe se desdobra em uma Teoria do Discurso que afirma que o ser dos objetos se constitui a partir de articulações no interior de totalidades discursivas. Nesse sentido, é possível 
observar uma forte ruptura com o materialismo de Marx, caracterizado pelos autores como idealista e essencialista.

De modo semelhante, se o enfoque pós-marxista afirma a centralidade dos antagonismos sociais como possibilidade de análise teórica das sociedades contemporâneas e da mudança social, tal como na teoria marxista, seu desenvolvimento posterior depende da ruptura com a visão racionalista da história e do abandono da contradição forças produtivas/relações de produção como seu fundamento. Desse modo, Laclau e Mouffe consideram o antagonismo e a divisão social constitutivos das relações sociais e descartam a ideia de que seja possível chegar a uma sociedade totalmente transparente e livre de conflitos. 0 antagonismo representaria os limites de toda objetividade. Por fim, Laclau e Mouffe desenvolvem uma nova abordagem da hegemonia, em que ligam a lógica político interpretativa de Gramsci à crítica filosófica radical, ancorando-se, sobretudo, no desconstrucionismo de Derrida.

Portanto, é possível observar, a partir da exposição acima, que embora os autores adotem formas discursivas oriundas do marxismo para compor o aparato conceitual do pós-marxismo, eles acabam rompendo com o pensamento de Marx nessa reformulação. A tentativa de repensar o socialismo, a influência de Gramsci e de Althusser constituem os principais legados do marxismo no enfoque de Laclau e Mouffe.

A análise permite afirmar que a releitura dos clássicos a partir de uma perspectiva desconstrucionista é, no mínimo, controversa, na medida em que implica uma ruptura com seus elementos constitutivos 9 . Apesar disso, os autores pós-marxistas parecem manter a preocupação de que a relação com os clássicos, por meio da desconstrução derrideana e de uma genealogia do presente, oriente-se pela busca contemporânea de conhecimento científico - aproximando-se, dessa forma, de outras abordagens encontradas na teoria social contemporânea, como é

\footnotetext{
${ }^{9}$ É importante destacar que Alexander (1999) já havia recorrido à desconstrução de Derrida para analisar a obra de Parsons e sua interpretação - já clássica - dos autores clássicos, destacando não somente a presença de determinados autores e obras específicas na construção do argumento teórico parsoniano, como também as ausências - relação que também será identificada em seus críticos.
} 
o caso da visão hermenêutica (Alexander, 1999) e do presentismo ${ }^{10}$ (Pyythinen, 2010).

Nesse sentido, Laclau e Mouffe oferecem um profícuo aparato conceitual de análise social e política das sociedades contemporâneas. Ao afirmar o caráter constitutivo do antagonismo e da negatividade do social, seu enfoque permite apreender as relações de poder que estão por trás do processo democrático assim como os principais desafios para a política democrática. O deslocamento do privilégio da classe social como categoria ontológica abre espaço para a abordagem de problemas cruciais das sociedades contemporâneas, como a proeminência de outras divisões sociais, como o gênero e a etnia. Ademais, a teoria neogramsciana da hegemonia permite pensar as novas formas de participação política, em que o consumo e os meios de comunicação de massa desempenham um papel central na constituição de identidades e das articulações hegemônicas. Embora autores como Nestor Canclini (1995) tenham se debruçado sobre esse fenômeno, a perspectiva de Laclau e Mouffe possibilita uma leitura mais crítica, na medida em que enfatiza o caráter constitutivo do conflito e das relações de poder.

É válido destacar também a disposição dos autores em apreender algumas das críticas feitas ao seu enfoque, assimilando importantes contribuições que inserem sua perspectiva nos principais debates da teoria social contemporânea, tais como a persistente tentativa de superar a dicotomia entre agência e estrutura, através de uma teorização do sujeito anterior ao processo de subjetivação; a discussão sobre a possibilidade de mudança histórica a partir da afirmação de seu caráter contingente e a superação da noção de classe como categoria universal para pensar os conflitos sociais e políticos. Esses e outros aspectos conduzem a um crescente interesse pela nova abordagem teórica proposta por Laclau e Mouffe, que tem exercido forte influência em diversas correntes teóricas contemporâneas.

\section{Referências}

\footnotetext{
${ }^{10}$ Enquanto a perspectiva hermenêutica defende a atualidade dos clássicos pela sua capacidade de conferir unidade ao campo sociológico, fornecendo um terreno comum de compreensão e discussão, o presentismo corresponde à interpelação de obras clássicas a partir de preocupações contemporâneas.
} 
ALEXANDER, Jeffrey. A importância dos clássicos. In: GIDDENS, A. TURNER, J. (orgs.). Teoria Social Hoje. São Paulo, Unesp, 1999.

BECK, U. GIDDENS, A. LASH, S. Modernização reflexiva: política, tradição e estética na ordem social moderna. São Paulo: Editora da Universidade Estadual Paulista, 1997.

CANCLINI, N. G. Consumidores e cidadãos: conflitos culturais da globalização. Rio de Janeiro: Editora da UFRJ, 1995.

DERRIDA, J. A estrutura, o signo e o jogo no discurso das ciências humanas in A escritura e a diferença. São Paulo: Editora Perspectiva, 2002.

FOUCAULT, Michel. A ordem do discurso. São Paulo: Loyola, 1999.

GRAMSCI, A. Concepção dialética da história. Rio de Janeiro: Civilização Brasileira, 1978a.

Maquiavel, a política e o Estado moderno. 3 ed. Rio de Janeiro: Civilização Brasileira, 1978b.

LACLAU, E. Política e Ideologia na Teoria Marxista: Capitalismo, fascismo e populismo. Tradução de João Maia e Lúcia Klein. Rio de Janeiro: Paz e Terra, 1978. A política e os limites da modernidade in HOLLANDA, H. B. (org.). Pósmodernismo e política. Rio de Janeiro: Rocco, 1992.

. Nuevas reflexiones sobre la revolucion de nuestro tiempo. Buenos Aires: Ediciones Nueva Visión, 1993.

. Identity and Hegemony: the role of Universality in the constitution of political logics in BUTLER, J.; LACLAU, E.; ZIZEK, S. Contingency, Hegemony, Universality. Londres: Verso, 2000.

LACLAU, E. MOUFFE, C. (2010), Hegemonía y estrategia socialista: Hacia una radicalición de la democracia. 3ed. Buenos Aires: Fondo de Cultura Económica de Argentina, 2010.

- Posmarxismo sin pedido de disculpas, in LACLAU, E. Nuevas reflexiones sobre la revolucion de nuestro tiempo. Buenos Aires: Ediciones Nueva Visión, 1993.

MENDONÇA, D. A noção de antagonismo na ciência política contemporânea: uma análise a partir da perspectiva da Teoria do Discurso. Rev. Sociol. Polit., Curitiba, n. 20, 2003, p. 135-145.

MOUFFE, C. Por um modelo agonístico de democracia. Rev. Sociol. Polit. Curitiba, n. 25, 2005, p. 11-23.

2009.

. Em torno a lo político. Buenos Aires: Fondo de Cultura Económica,

PYYTHNEN, O. Simmel and the "social". Basingstoke, UK, Palgrave, Macmillan, 2010.

TORFING, J. New theories of discourse: Laclau, Mouffe and Zizek. Mass.: Blackwell, 1999.

Recebido: 05 jan. 2019

Aceito: 20 jan. 2019 